\title{
ARQUITETURA E ESPAÇOS ESCOLARES NA ESCOLA PORTUGUESA (PERÍODO DO SÉC. XIX E SÉC. XX): LUGARES DE MEMÓRIA
}

\author{
Ernesto Candeias Martins ${ }^{1}$
}

\begin{abstract}
Resumo:
O estudo trata de arquitetura e espaços escolares, numa análise histórica-educativa, no período do séc. XIX e parte do séc. XX. O marco teórico-conceptual assenta em alguns estudos especialmente de Alegre, Barroso, Benito Escolano, Burke, Carvalho e Viñao Frago, que nos leva a utilizar uma metodologia hermenêutica ancorada ao âmbito da História da Educação ou História das Instituições Educativas. Temos como objetivos: analisar o espaço escolar como lugar; compreender o espaço escolar como elemento intrínseco ao quotidiano da escola. Temos 3 pontos de análise: espaço como elemento crucial da relação arquitetura escolar-educação; espaço escolar como lugar e território da materialidade física; organização educativa, a classe e estruturação do tempo escolar. A discussão, interpretação e releitura do espaço escolar focaliza os projetos arquitetônicos de cada época.
\end{abstract}

Palavras-Chave: arquitetura escolar; espaço escolar; organização educativa; lugar de memória

\section{SCHOOL SPACES AND ARCHITECTURE IN PORTUGUESE SCHOOL (PERIOD OF THE 19th AND 20th CENTURIES): PLACES OF MEMORY}

\begin{abstract}
The study about architecture and spaces, in a historical analysis-educational, in the period of the 19th century and part of the 20th century. The theoretical-conceptual framework is based on some studies especially Alegre, Barroso, Benito Escolano, Burke, Carvalho and Viñao Frago, who leads us to use a hermeneutical methodology anchored to the context of the history of education or history of Educational Institutions. We have as objectives: to analyze the school space as place; understanding the school space as intrinsic element to the everyday life of the school. We have 3 points of analysis: space as key element of school architecture-education relationship; school space as place and territory of the physical materiality; educational organization, the class and structuring the school time. The discussion, interpretation and review of school space focuses on the architectural projects of each season.
\end{abstract}

Keywords: School architecture; school space; educational organization; place of memory

\footnotetext{
${ }^{1}$ Doutor em Ciências da Educação do Instituto Politécnico de Castelo Branco, do Dept.. CSH da ESECB, Rua Prof. Faria de Vasconcelos, 6000-262-Castelo Branco/Portugal. Email: ernesto@ipcb.pt
} 


\section{Introdução}

A análise pedagógica aos espaços constitui uma linha de investigação historiográfica, que destaca a potencialidade educativa do(s) espaço(s) na base da interdependência que mantém com o sujeito da educação $e$ ato educativo, principalmente ao nível comunicacional, das relações, ações quotidianas, discursos e sentimentos, que são componentes da matriz vetorial 'homem-espaço envolvente' (GARCÍA DEL DUJO \& MUÑOZ RODRÍGUEZ, 2004). Os discursos desta pedagogia clarificam semanticamente os termos espaço, meio, ambiente, lugar, território, contexto, etc., em que cada um deles denota uma particularidade que o distingue dos outros e outorga-lhe um sentido próprio (COLOM, 2005).

Esta pequena viragem conceptual implica não pensar apenas no espaço em que os indivíduos vivem e se relacionam, configurando e construindo as suas identidades, mas também construir histórica e socialmente o potencial educativo do próprio espaço. Ora, esta perspectiva desenvolve postulados metodológicos que demonstram que a Pedagogia, como ciência social dos espaços, parte das interdependências entre aspetos socioculturais e físico-geográficos do espaço com os indivíduos. Ou seja, o espaço é valorizado pela Pedagogia como dimensão intrínseca ao fenômeno ou processo educativo.

Este terreno conceptual é pantanoso e difuso o que dificulta o estudo dos espaços na interdependência entre os sujeitos e os seus âmbitos relacionais. A forma de organizar o espaço repercute no desenvolvimento das relações nas organizações o que determina a participação dos indivíduos nessa estrutura. De facto, o conceito de espaço aglutina o conteúdo de todos os outros conceitos afins, apresentando um leque amplo de conotações que se desprendem e cuja amplitude o converte como referente (COLOM, 2005). Falamos de espaço aludindo a um campo categorial, mais que a uma categoria determinada. Ora este enfoque integrador de espaço reconduznos a matizes conceituais que permite ao sujeito (da educação) desenvolver-se no tempo e construir a sua identidade e os processos de socialização. Mas, a nossa análise assenta exclusivamente na conceção do espaço escolar, dentro arquitetura escolar, e a sua relação com a organização educativa e tempo escolar nas instituições educativas (escola primária). 
O espaço escolar é um cenário e o edifício, tal como outros espaços institucionais, constituem um contendor dotado de significados. Para Viñao Frago (2008, p. 17) os espaços escolares são como lugares, produto das rotinas e relações pessoais, geradas no interior dos edifícios e de tudo o que se possa considerar a invisibilidade da educação, configurando os vários códigos disciplinares, os discursos e as representações socioculturais e que perduram no imaginário coletivo. Os próprios edifícios escolares (arquitectura), integrados na cultura material da educação, são lugares carregados de simbolismo, discursos e imaginários coletivos (recordações), que conjuntamente com os manuais, legislação, material didático incidem nos processos ensino-aprendizagem dos alunos e, por isso, configuram as representações socioculturais da escola (ESCOLANO BENITO, 2011, p. 65). Cremos que os espaços, com a sua dimensão simbólica e materialidade constituem-se em instrumentos de controlo (poder e disciplina), lugares de memória e de sociabilidade/socialização, que de forma (in)direta reproduzem discursos de poder existentes em cada época. Assim, os espaços são como lugares de memória, de socialização e de reprodução de uma determinada ordem social e política.

Abordaremos a arquitetura e espaços escolares e conceitos afins, numa análise histórica-educativa, no período do séc. XIX e parte do séc. XX. O nosso marco teóricoconceptual assenta, especialmente nos estudos Alegre, Barroso, Benito Escolano, Burke, Carvalho e Viñao Frago, Utilizaremos um argumento, de índole hermenêutico e fenomenológico, ancorado no âmbito da $\mathrm{H}^{\mathrm{a}}$ da Educação/H. Educativas pretendendo ser um contributo historiográfico. Temos como objetivos: analisar o espaço escolar como 'lugar' em que se produz relações interpessoais, oriundas das interações professor/aluno-espaço, sendo fundamento da ação educativa desenvolvido que tem em conta vetores plurais e diversos caracterizadores do próprio espaço; compreender que o espaço escolar como um 'fenômeno próximo', elemento intrínseco ao quotidiano da escola, faz que os sujeitos se expressam num território contextualizado por ações e relações; compreender que a educação tem a necessidade e pertinência de estar organizada e estruturada temporalmente, na base dos espaços. 
O texto está estruturado metodologicamente em 3 pontos: o espaço como elemento essencial da relação arquitetura escolar-educação; o espaço escolar como lugar e território da materialidade física: compreender a organização educativa, o conceito de classe e a estruturação do tempo escolar, como resultado da institucionalização da escola. A discussão, interpretação e releitura do espaço escolar focaliza os projetos das escolas, num diálogo com a política educativa de cada época. Daí a importância da apropriação dos espaços escolares, pelos atores e as relações entre as suas representações e identidade nas instituições educativas.

\section{1.- O espaço elemento fulcral na relação 'arquitetura escolar - educação'}

Se a arquitetura é o ambiente e cenário no qual desenvolvemos e realizamos a nossa vida, o espaço considera-se o seu instrumento. Um edifício com a sua arquitetura integra: a fachada mais ou menos grandiosa com janelas, varandas e portas de acesso; espaço interior configurado pela forma, textura, cor, luz natural, objetos (materialidade) e valores simbólicos de cada obra arquitetónico e, daí ser considerado um representante dessa arquitetura; o espaço externo (urbanístico) limitado pelo edifício e pela sua envolvência, formando parte do conjunto significativo da vida sociocultural e comunitária, refletindo os elementos econômicos, políticos, desportivos/recreativos, estruturas institucionais, crenças e valores (ALEGRO, 2009). Todo o edifício edificado (e não edificado) apresenta uma pluralidade de valores (econômicos, técnicos, sociais, funcionais, artísticos, decorativos, espaciais, etc.), que estão em sintonia com as necessidades dos utilizadores e/ou das funções a que se destina. No caso escolar, a arquitetura e o cenário apresentam-se com os seus espaços, numa organização dependente da dimensão temporal e duma carga simbólica, representando e reproduzindo uma concepção de educação, uns valores, um modelo político e social e uma determinada relação de poder. Assim, os espaços integrantes na arquitetura escolar influenciam o processo educativo, a formação social, moral e para a cidadania, tal como os conteúdos curriculares.

De facto, a arquitectura escolar é um termo que tem vindo a consolidar-se, pois os espaços que integra ou envolve revelam-se como um cenário que implica o 
surgimento de comportamentos diferenciados e apresenta sistemas de estímulo que despoletam certas condutas humanas. Este discurso remonta-se à pedagogia de Rousseau, Pestalozzi e Fröebel, ao reconhecer, gradualmente, o espaço escolar como uma parte integrante e fundamental da instrução/ensino da criança. Deste modo, os espaços nas escolas constituem o reflexo das preocupações pedagógicas, mas também espelham o meio em que se inserem, sendo em alguns casos parceiros do desenvolvimento comunitário. Esta preocupação socioeducativa deu atenção à criança e à sua infância, já que ela carrega consigo os espaços onde vive e marca os lugares que habita ou aprende. Neste sentido, Dudek (2000) aponta para a importância do ambiente no desenvolvimento das crianças, em particular o ambiente arquitectónico, já que à medida que ela cresce passa da atitude egocêntrica para a alocêntrica e, por isso, a(s) vivência(s) do espaço, faz dele a sua construção. Daí que a educação, no dizer de Nóvoa (2005, p. 30) ao ser entendida como um direito fundamental repercutiu-se num aspeto construtivo e determinante.

O conhecer/observar e experimentar o(s) espaço(s) passa a ser o objetivo da prática da criança, ao construir o seu conhecimento e dando significado aos seus atos espaciais. É nessa apropriação do espaço, que a criança compreende a evolução das mudanças na sua personalidade. No caso do ambiente escolar e, em particular, da arquitectura escolar, constitui uma parte desse seu desenvolvimento e crescimento, de ampliação de saberes e experiências socioculturais, de adequação às regras, de promoção de relações e de estrutura das hierarquias enriquecedoras. $O$ edifício escolar passa a ser o espaço de ensino que se identifica como uma entidade própria, com autonomia e propriedades espaciais e funcionais aceitáveis. É o resultado duma arquitectura com identidade, produto de um leque de aspectos morfológicos visíveis e funcionais, com a finalidade de ensinar.

Só a partir da segunda metade do séc. XIX reconhecemos uma nova tipologia de edifício público, num momento em que despontava uma série de novas tipologias das existentes, como as escolas portuguesas Conde Ferreira, a meados do séc. XIX. A expansão da revolução industrial implicou a construção de fábricas, hospitais, e edifícios públicos, com uma tipologia específica que, conjuntamente com as instituições educativas, foram muito reconhecidas. As escolas associam-se à vontade 
(política), por vezes de índole benfeitora/filantrópica, de reforma social, enquadrandose nas transformações do urbano e comunidade. É o caso das escolas próximas às fábricas, destinadas a acolher crianças no período laboral dos pais.

A realidade portuguesa, no séc. XIX, pautou-se com reformas educativas (Costa Cabral, Passos Manuel) e com a construção dos edifícios escolares, num processo lento e custoso, apesar da prioridade pela instrução pública, reiterado com a eclosão do liberalismo, que previa a sua gratuitidade. Essa obrigatoriedade de frequentar a escola primária, com mais de 7 anos de idade ficou legislada no Regulamento Geral da Instrução Primária, de 7/09/1835. A retoma do ensino privado pelos jesuítas a partir de meados do séc. XIX até 1910, não impediu que as reformas educativas privilegiassem a construção de edifícios para escolas primárias, pois até finais desse século o ensino, acontecia em edifícios existentes com grande diversidade morfológica, desde construções a pequena escala, por exemplo a casa/habitação do professor, antigos conventos ou colégios jesuíticos, palácios até dependências municipais reutilizadas, etc.

Temos que chegar ao séc. XX para vermos consolidada a autonomia das escolas, como equipamento de interesse público, o que permitiu a análise arquitetônica e pedagógica das valências dos edifícios, enquanto espaços onde se materializam ideias/modelos pedagógicos e estudos sobre as especificidades das estruturas de organização dos diferentes graus de ensino. Assim, os edifícios escolares passam a refletir as estruturas sociais e da faixa etária a que se destinam, perpetuando as hierarquias que delineiam o poder e a cultura vigente, mas mantendo como ponto em comum, a classe, que constitui a célula base para as suas diversas combinações arquitetônicas (ALEGRE, 2009, p. 48). A classe constitui o elemento simbólico ao institucionalizar-se como o modelo 'natural da escola', ou seja, o edifício escolar assenta na matriz pedagógica da classe na perspetiva de desenvolvimento da escola pública, (BARROSO, 2001, p. 64). Aliás, a classe, apesar da influência e de se apresentar de diferentes formas e com variações nas suas composições espaciais internas, devido às premissas das teorias pedagógicas e espaciais, nunca deixou de ser o vetor crucial no sistema educativo. Ainda hoje o sistema de ensino público está 
organizado na base da classe, modelo que tem a virtude de materializar o ensino em torno de uma pedagogia coletiva (TRILLA, 2002).

Se analisamos os tipos da arquitetura (edifícios) da rede das escolas primárias portuguesas, projectadas e construídas, a partir de finais do séc. XIX e séc. XX, reconhecemos a responsabilidade do Estado e, em alguns períodos dos municípios, na área da construção. Na verdade, a escola na Europa instala-se em edifício próprio no séc. XIX, quando se fomenta o ensino obrigatório. É a época em que a tipologia do edifício público é reconhecida no conjunto das reformas sociais (ALEGRE, 2009, p. 2). Ao valorizar-se a arquitectura escolar, esta assume umas morfologias específicas, configurações espaciais e funcionais próprias, que implicam legibilidade de autonomia arquitectónica, em especial, no período das reformas sociais, que se preocupavam em colmatar necessidades de aprendizagem infantojuvenil devido ao seu elevado analfabetismo (CARVALHO, 1986).

Em determinados períodos, a arquitectura escolar, em Portugal, serviu também aos governos para incorporar as suas teorias sociais e políticas. Assistimos em Portugal no período da 'ditadura do Estado Novo' ou salazarista a uma renovação simbólica, que incide na trilogia de 'Deus, Pátria e Família', através de uma eficaz formalização nas escolas. Aos arquitectos possibilita-se a afirmação do seu estatuto profissional, com a construção de muitos edifícios públicos modernistas (CARVALHO, 1986). Este regime político salazarista, saído da revolução de 1926, promove uma política de obras públicas, a grande escala, incluindo nas décadas de 40 e 50 com os projetos escolares designados por Plano dos Centenários I a IV. O edifício da escola teve segundo a região portuguesa diferenças nos materiais de construção e na fachada, por exemplo nos projetos de Rogério de Azevedo e Raul Lino, no Plano dos Centenários, Fernandes de Sá e Fernando Peres, etc.

Por conseguinte, a realidade da arquitectura escolar portuguesa foi muito contida na sua evolução, seja ao nível das correntes de educação, bem patente nos modelos arquitectónicos e na forma de ensino adoptado, seja ao nível do desenvolvimento dos métodos construtivos e ativos assentes no uso de várias tecnologias e materiais didáticos. Com efeito, escasseia uma análise comparativa da influência sofrida em Portugal, ao nível conceptual, pela produção de edifícios 
escolares em outros países europeus e, ainda a forma da aplicação dos pressupostos que Ihes estão subjacentes, em consequência, das semelhanças ou diferenças em políticas educativas, culturais e geográficas (ALEGRO, 2009).

Na verdade, há uma relação entre a arquitetura e/ou edifícios (projeto) com os espaços escolares, integra o património histórico-educativo da cultura material escolar. Ou seja, o edifício escolar nos seus diversos espaços, com muros, paredes, janelas, portas e mobiliário, envolvido por jardins e espaços abertos, constitui no seu conjunto elementos ativos configuradores da experiência escolar e da compreensão da educação (BURKE, 2005, p. 494). Ora esses espaços foram-se especificando, com uma tendência a estabilizaram-se na sua configuração morfológica ao ensino.

\section{2.-O espaço escolar como lugar e território de materialidade física}

O espaço escolar tem vindo a ser analisado no âmbito da História da Educação nas últimas décadas, sendo um campo de investigação emergente e dominante, silenciado perante as práticas educativas, que procura compreender a cultura escolar. Historiograficamente a análise à arquitetura e espaços escolares permite-nos compreender os modos como se concebeu a estrutura organizativa numa instituição educativa. Isto é, a organização do espaço escolar está condicionado pela própria arquitetura, mas raramente a mesma responde às necessidades que vão surgindo no tempo histórico. Desde a análise aos diferentes projetos constatamos que os conhecimentos pedagógicos dos espaços foram fundamentais para a sua distribuição, localização e funcionalidade, seguindo critérios de organização geral. O espaço, na escola/instituição educativa, concebe-se como educador de si mesmo, gerando interações, relações, metodologias e necessidades do ensino, passando a ser protagonista no processo educativo e na socialização e convivência, segundo as atividades desenvolvidas nele. Espaço e objetos consideram-se a 'cultura material' das instituições escolares, um objeto de análise privilegiado, onde se materializa '[...] lo pensado, lo propuesto, lo prescrito y lo realmente acaecido' (VIÑAO FRAGO, 2008, p. 17). 
Se efetuarmos uma descrição ao artifício da estrutura vetorial, proveniente das várias áreas científicas, que outorgam significado educativo ao espaço deduzimos que este é entendido como 'lugar' onde as pessoas se identificam, encontram significados de referência, ativam relações e emoções, comunicam-se e, consequentemente constroem um sentido de pertença mútua com o(s) espaço(s). Daí, a importância dos espaços nos processos de desenvolvimento das pessoas e, em particular, nos alunos no âmbito escolar, produzindo uma covariância entre 'sujeito-espaço', útil para fundamentação e programação das ações educativas.

Analisemos alguns vectores ou dimensões dos espaços. Um primeiro vetor é o de territorialidade ou experiência territorial em que os alunos vivem e interagem com os espaços (função social/cultural, de interação, dominação e controlo), convertendose em lugares de significado, de relações de proximidade e de apego ou apropriação. Daí que é nos espaços onde os alunos adquirem pautas de comportamento e atitudes relacionadas com a disciplina no espaço. Um segundo vector é o da quotidianidade do espaço, que nos desvela a tramado situacional dos alunos, quer em termos simbólicos, comunicacionais e afetivos que ele produz na vida escolar. Outro vector é o da relação 'sujeito da educação-espaço' no âmbito afetivo emocional nas transações e interações que o(s) espaço(s) provocam nas relações (COLOM, 2005). Este vector relaciona-se com um outro que é o relacional, já que a realidade espacial dos sujeitos no dia-a-dia da escola é relacional e, por isso, a distribuição (temporal) e estrutural do(s) espaço(s) explica, facilita e inibe determinados comportamentos relacionais dos alunos. Ou seja, estes devem ser elementos integrantes do espaço que reconhece, utiliza e transforma ao experimentá-lo e interage com os outros. Na nossa perspetiva o espaço escolar como lugar proporciona o encontro, a inter relação, a comunicação e abertura à incorporação de outros agentes e sucessos educativos, para além dos objetivos propostos. Um outro vector, que constitui o eixo fulcral do espaço é o do significado sociocultural (GARCÍA DEL DUJO \& MUÑOZ RODRÍGUEZ, 2004), ou seja, o significado dos espaços referente à interpretação como sistemas criadores de estruturas (físicas, sociais, culturais) que permitem o desenvolvimento e renovação dos esquemas de pensamento e ação dos sujeitos no ato educativo. Por último, o 
vector da comunicabilidade do espaço no ato educativo, eixo essencial do processo educativo e das possibilidades de comunicação e interação (ROMANÁ BLAY, 2004).

De facto, o espaço escolar é como um território de materialidade física que se constitui num elemento fundamental na configuração da cultura de uma instituição educativa, tal como a distribuição e uso do tempo escolar, dos discursos e da comunicação utilizada na instrução e formação ministrada. No dizer de Viñao Frago (2004, p. 279) o espaço é lugar e território de materialidade, pois enquanto o espaço se projeta, se observa e se imagina o lugar constrói-se e, por isso, é uma construção oriunda do espaço como suporte disponível para ser utilizado e vivenciado. Assim, a constituição do espaço como lugar implica o resultado de uma ocupação e utilização pelo indivíduo. Essa ocupação do espaço institucional e a sua reconversão em lugar escolar provoca vivências dos sujeitos da educação, que se configuram num 'território' de relações. No dizer de Viñao Frago (2004, p. 280) a relação objetiva entre 'espaçolugar', expressa pela cultura material da escola, articula-se com a relação subjetiva 'espaço-território' (interno/externo, aberto/fechado) de vivências e experiências individuais e de grupo. Deste modo a configuração dos espaços numa instituição educativa, no sentido de lugar específico e território, relaciona-se com a arquitetura do edifício e da sua envolvência, na base de princípios, significados e representações subjacentes às ideias, aos discursos e práticas pedagógicas.

Há fatores que condicionam os espaços escolares: os externos (situação geográfica, tendo em conta o clima, a orientação do edifício, iluminação, ventilação, aquecimento, material de construção, número de alunos, condições de acesso e acústicas, etc.); e os internos para ministrar um ensino de qualidade tendo em conta as metodologias didáticas, as tecnologias de ensino, as relações e funcionalidade dos próprios espaços (direção, secretaria, laboratórios/oficinas, tutórias, sala de professores, salas de aula, salas multiusos, biblioteca, ginásio, etc.). Assim, para que um espaço se considere escolar deve cumprir, por exemplo os seguintes requisitos: a intencionalidade; os elementos didático-pedagógicos; a estrutura (não limitada às paredes do seu formato); a dinâmica dos sujeitos ativos que os ocupam; o material didático disponível e mobiliário adequado. De facto, os espaços devem respeitar as caraterísticas, os ritmos e necessidades dos alunos e do processo ensino- 
aprendizagem. Ou seja, irem ao encontro das necessidades fisiológicas (higiene, alimentação, segurança e conforto), afetivas, de autonomia, de movimento (tempos livres), de socialização, de exploração e conhecimento, de modo a criar diferentes ambientes que permitem $o$ desenvolvimento integral e a aquisição de capacidades/competências dos alunos, sendo estes os protagonistas das suas aprendizagens (ESCOLANO BENITO, 2003, p. 368).

Neste sentido o espaço escolar converte-se num elemento material da educação, um meio que as instituições educativas possuem e, por isso se define como o continente e conteúdo das diferentes situações de ensino-aprendizagem. É continente porque permite que no seu interior se produza o processo ensinoaprendizagem e é conteúdo porque condiciona os saberes, as destrezas e atitudes que se ministram no próprio espaço. Este outorga qualidade ao ensino, mas também condiciona, favorece ou dificulta o desenvolvimento e aprendizagem dos próprios alunos. Sabemos que todo o espaço tem um caráter educativo e, por isso, numa instituição escolar não limitemos as possibilidades de aprendizagem às salas de aula, pois qualquer espaço projetado estrategicamente pode ser protagonista do processo ensino-aprendizagem (educação formal e não formal), garantindo o desenvolvimento integral do aluno (TRILLA, 2002). É sabido que o sujeito da educação estabelece um vínculo com o contexto em que se situa (fenomenologia do espaço), seja desde o enfoque ecológico (Bronfrenbrenner) ou do construtivismo social e cognição situada (Vygotsky, Leave) ou desde a perspectiva antropológica a ideia de espaço como sistema cultural informal (S. Hall). Lembremo-nos que a Escola Nova, com um pensamento pedagógico autoestruturante, propunha detrás de cada edifício escolar uma possibilidade pedagógica e, por isso, ela necessitou de uma materialidade arquitetónica, já que a arquitetura escolar predominante na época respondia a princípios pedagógicos da escola tradicional. Daí resultou alguns projetos arquitétónicos (modelos autoestruturante), impregnados de conceitos pedagógicos, como por exemplo o método Waldorf de R. Steiner (arquitetura antroposófica), método Montessori na 'Casa dei Bambini', modelo educativo de Salzmann de Etievan, etc, com a sua materialização arquitetónica com a pedagogia. 
Por conseguinte, a configuração do espaço escolar em lugar implicou estabilidade, independência física, especificidade/funcionalidade. Essa configuração do espaço escolar, no sentido de lugar específico e território, relaciona-se com a conceção da arquitetura escolar, que constitui um discurso material e forma de linguagem não verbal, transmissora de hierarquias, valores, princípios de ordem, de disciplina e poder, de classificação (tipologia), de representações mentais (com evocação), ou seja, num leque de significados simbólicos mais ou menos evidentes. É nesta configuração que captamos os princípios, significados e representações subjacentes às ideias, às propostas e práticas que, para Viñao Frago (2004, p. 281), são o lugar e o território específico do espaço escolar.

Nessa distribuição e uso dos espaços num edifício consideramos o espaço escolar e o espaço segmentado, que são diferentes entre si pelo seu uso e funcionalidade, seja em zonas edificadas e não edificadas e/ou no interior de cada uma a função ou funcionalidade dos espaços livres e abertos a outras tarefas. Por outro lado há também relação do espaço escolar com outros espaços, com dimensões e disposições internas no edifício, como seja a biblioteca, museu, laboratório(s) salão de atos, ginásio, capela e jardim/pátio interior. Para além dos espaços propriamente produtores de cultura material da educação (salas de aula, laboratórios, museu, sala de reuniões e de estudo, biblioteca) no edifício, há espaços específicos para a direção/secretaria e economato, gabinete médico, antropométrico ou de enfermagem, sala de estar, refeitório(s), etc. Assim, desde a sua elaboração, o projeto arquitetónico escolar apresentou propostas teórico-práticas de edificação (projeto oficial/municipal ou particular) que incluía a disposição dos espaços em função da: especificidade de funções a que se destinavam; localização no interior do edifício; acessibilidades e articulação com os outros espaços; dimensão em função das atividades e/ou tarefas educativas a desenvolver; disposição no projeto do edifício (VIÑAO FRAGO, 2008).

\section{3.- Organização educativa e estruturação do tempo escolar}

Aquando da substituição da Igreja pelo Estado na organização do ensino este não sofreu muitas alterações ao existente de classe/sala de aula. Para Barroso (2001, 


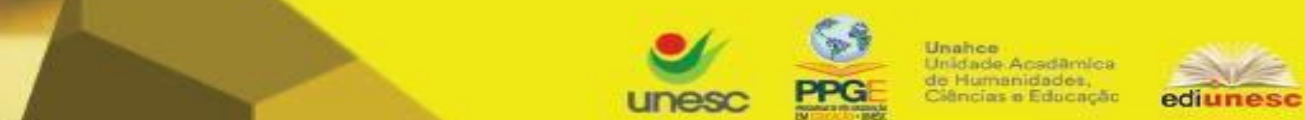

Criar Educação, Criciúma, v. 9, №2, Edição Especial 2020.- PPGE - UNESC - ISSN 2317-2452

p.64) '[...] esta matriz constitui uma extensão, ao ensino simultâneo, dos pressupostos e métodos pedagógicos do ensino individual, enquanto relação face a face de um mestre-escola com o seu discípulo'. Com efeito, as preocupações à volta da organização educativa e espacial da sala de aula surgem com o modo de ensino simultâneo e ensino monitorial ou mútuo. Recorremos a M. ㄹ Alexandra Alegre (2009, p. 27) na explicitação desses 'modos de ensino' no séc. XIX:

'[...] ensino individual, em que cada aluno recebe direta e separadamente as lições do professor ensino simultâneo, que tem por objeto tornar ao mesmo tempo participantes duma lição, dada pelo mestre e os alunos capazes de a receber; ensino mútuo, aliviando o professor pela adjunção de auxiliares tirados da própria escola e denominados 'monitores', entrega--Ihes a direcção dum grupo ou subgrupo e aos alunos de tais grupos devem eles ensinar o que aprenderam do método; ensino misto, consiste em receber numa escola simultânea alunos repetidores, tendo simplesmente por fim auxiliarem o mestre na instrução de muitos dos seus condiscípulos, não tomando porém senão uma parte puramente mecânica ou, pelo menos, muito simples no ensino"

Os modos de ensino permitiam tornar reflexiva a aprendizagem, no pressuposto de ensinar um grupo de alunos como se de um só se tratasse. Durante a segunda metade do séc. XIX, os métodos de ensino alternavam-se entre o simultâneo e o misto, sendo o modo simultâneo o que perpetuou no séc. $X X$.

A organização espacial do método mútuo dava preponderância à actuação do mestre perante os alunos, onde o espaço ocupado por cada um compreendia o intervalo que separava os bancos em fila com as mesas com a secretária e respectivo estrado. A planta dessas salas (dimensão $21 \mathrm{~m} \times 10 \mathrm{~m}$ ) definia os espaços para 0 mobiliário e distribuição de uma dezena de alunos, existindo também círculos de leitura, pronúncia e aritmética para 8 ou 9 alunos, junto à parede onde as crianças se reuniam em torno de quadros suspensos (ALEGRE, 2009). Tratava-se de uma sala comprida em que a localização da mesa e cadeira do professor, era no extremo da sala, junto ao quadro (móvel com tripé ou fixo) e diante de um número elevado de alunos, em que as paredes estavam decoradas com símbolos e/ou mapas (PINTASSILGO \& COSTA, 2007, p. 109). O espaço central era ocupado por filas contínuas de carteiras e bancos corridos para 8 até 16 alunos, voltadas na direcção da mesa do mestre. Muitas vezes cada uma destas filas era coordenada por um 
monitor. Garantia-se na sala de aula uma boa ventilação e luminosidade, com janelas largas e altas, distribuídas de forma equidistante pelas paredes longitudinais, de forma que a visibilidade para o exterior fosse impedida, para além de um pé de teto muito alto. Para uma repartição do calor existiam aquecedores a vapor ou a lenha, sendo o chão de terra batida.

De facto, o espaço da sala de aula foi, segundo Viñao Frago (2008), a partir de meados do séc. XIX, a célula base da estrutura de qualquer edifício escolar, apesar de ter havido várias formulações pedagógicas e espaciais, resultantes da idade dos alunos e graus de ensino (disposição do mobiliário que induz a diferentes posições dos alunos e professor). Para Alegre (2006, p. 39), o modo de ensinar '[...] corresponde à forma de organizar o ensino na sala de aula' e o método à '[...] forma de dirigir e guiar o processo de ensino-aprendizagem'. Ora estes pressupostos para A. Nóvoa (2005, p. 48) são os componentes estruturantes da relação 'professor-aluno' na sala de aula e da própria composição espacial, dando como resultado uma matriz organizativa do sistema escolar. A classe surgiu pela necessidade de tornar possível o ensino coletivo e, assim ela adaptou-se ao modelo de ensino ministrado.

Lembramos, também que as críticas da Escola Nova à escola tradicional se baseavam na ideia duma pedagogia activa, promotora da construção do saber na criança, a qual devia estar motivada pelos seus interesses, assim como propor conceitos, na base de experiências, e no contacto com a natureza. De facto, a escola nova foi uma escola por medida, que teve em Rousseau, Pestalozzi e Fröebel os seus antecedentes, os quais sedimentaram e materializaram essas ideias em escolas e infantários que foram '[...] como verdadeiros laboratórios de ensaio' (ALEGRE, 2009, p. 37). Fröebel concebeu os jardins-de-infância como as primeiras idealizações arquitectónicas, fruto de uma prática educativa específica que, em Portugal, originou o projecto da Escola Fröebel, no Jardim da Estrela, em Lisboa, em 1882, da autoria do arquitecto José Luís Monteiro (CARVALHO, 1986).

Esta preocupação em relacionar a criança com os espaços do exterior, objectivo presente no modelo pedagógico do movimento da Escola Nova, teve impacto na arquitectura escolar, de tal modo que a concepção do edifício já não era indiferente às características do meio onde se insere, sendo os projetos do arquiteto 
Raul Lino um bom exemplo em Portugal. De facto, a localização do terreno para construir a escola passa a ser fundamental, ao ser considerado parte do 'espaço educativo' (ALEGRE, 2009, p. 49). O edifício escolar passou a integrar os princípios da Escola Nova, inicialmente e de forma experimental no ensino privado, prolongandose depois às escolas públicas. O repensar da formalização do espaço da sala de aula, incrementou a sua relação com o exterior, mediante a introdução de mais aberturas (garantindo, também a sua higienização), uma flexibilização do uso do espaço construído potenciando a sua exterioridade (abertura da escola à comunidade) e a concepção mais ergonómica dos equipamentos e mobiliário escolar, como resposta às novas metodologias de ensino o que reforçou as práticas educativas. Tudo isto transformou a morfologia dos edifícios escolares do séc. XX.

Em relação ao tempo escolar sabemos que este especificou-se aquando o processo de institucionalização da escola, sendo distinto dos outros tempos da vida, havendo tempos em que o ritmo da escola (sineta, sino) influenciava os ritmos de vida comunitária. Pouco a pouco diferenciam-se e a escola toma o lugar de várias formas de educação e formação, em função das camadas sociais e das conjunturas de política educativa. Assim, a imposição do tempo escolar dilui-se na sua inserção na vida das crianças, jovens e adultos, apresentando-se como uma coerção ou obrigação da instrução ministrada. Com reconhecimento pela sociedade da escola como lugar de instrução e/ou formação da infância e juventude, o tempo na estrutura organizativa escolar passa a ser gradualmente coercitivo na repetida e constante exigência disciplinar dos comportamentos e aprendizagens, convertendo-se numa norma social obrigatória e, daí a separação dos tempos na vida comunitária, no trabalho, na família, nos tempos livres/recreio e no tempo escolar, de tal modo que implica finalidades, capacidades, critérios de avaliação distintos (ESCOLANO BENITO, 2000). É um facto que a obrigatoriedade do tempo escolar teve resistência bem evidente no fenómeno do absentismo e falta de assiduidade dos alunos. A ordem do tempo escolar é um construto cultural e pedagógico, sabendo que tempo e espaço escolar não são uma estrutura neutra onde se esvazia a educação/ensino (ESCOLANO BENITO, 2003, p. 369). A arquitetura do espaço e o tempo escolar implicam um discurso e um sistema de relações, que no fundo não é outra coisa que um sistema de poder. Não são 
neutros, nem na sala de aula, na organização das hierarquias na relação professoraluno, nem por disciplina/matéria e tampouco no tempo de recreio ou tempos livres. Historicamente à medida que aumentou o número de alunos surgiram novos modos de ensinar, que obrigaram a ter espaços específicos, havendo uma regulação do tempo, de modo a haver uma distribuição equitativa dos saberes/matérias. Desta forma surgiram as ideias de organização moderna da escola, com o ensinamento dos conteúdos marcados pelo tempo (DOMÈNECH \& VIÑAS, 1997).

\section{Ideias a reter (Não) conclusivas}

A História da Educação investiga o que se passa no interior e na envolvência da instituição educativa/escolar (arquitetura escolar e cultura material da educação), aprendendo e analisando os elementos configuradores que lhe conferem identidade própria, isto é, que lhe dão sentido no cenário sociocultural do que foi os espaços destinados à instrução ou ensino. Margarida Felgueiras (1998, p. 150) considera esse 'lugar' de memória do ensino, no quotidiano institucional em que ocorreu, os materiais, os artefactos, os utensílios, os espaços e os seus objetos, etc. M. Certeau (1996, p. 209) considera-o um 'sítio histórico', de memória e cultura material da educação, impreterível de interpretações, de relatos e narrativas. Sabemos que ao caminhar pelos espaços escolares, onde aprendemos, proporciona-nos a apropriação da sua topografia, num percurso mapeado pela sua visibilidade e/ou invisibilidade, que nos marca e constrói memória. Temporalmente as relações de apropriação dos espaços vão sendo reinventados, não só individual ou de grupo, como pela própria instituição. A diferenciação entre 'lugar' (estável, congelado) e espaço (vivo em interações e poderes) permite-nos considerar este, segundo Certeau (1996, p. 202), como um 'lugar praticado' e, por isso, compreende um cruzamento, um movimento contraposto ao de lugar, como ordem e relação entre elementos posicionais entre si (preestabelecidos). Assim, o lugar possibilita relatos dos espaços observados, na forma diferente de decorrência dos atores, dos sucessos e acontecimentos, desde do projeto de arquitetura ao da temporalidade (BONDIOLI \& NIGITO, 2011). Os espaços escolares configuram-se e vinculam-se às ações de sujeitos históricos e, por isso, não 
são neutros, mas sim lugares carregados de significados, que influenciam a nossa educação e, assim, historicamente eles falam e educam (BATANAZ, 2003, p. 243). A educabilidade desses espaços exige uma correlação entre 'arquitetura escolarconteúdo educativo' gerando cultura material, pois qualquer modelo arquitetónico de escola configura uma determinada pedagogia, modelo/metodologia de ensino (BURKE, 2005, p. 490).

Por outro lado, o espaço da sala de aula constitui o eixo à volta do qual se estruturaram os edifícios escolares, contudo a classe constitui o contendor onde se materializa as atividades que, teoricamente, justificam a existência dos restantes espaços (edificados ou não, interiores/exteriores) da instituição. A distribuição dos espaços construídos refletem a relevância atribuída às funções ou atividades que neles se realizam. Daí haver uma lógica interna, na estrutura de organização educativa, em função do tempo (escolar) atribuído, o que indica a funcionalidade a que se destinam os espaços. Assim, a vida quotidiana escolar converte-se num campo de estudo para a História da Educação.

Analisamos o conceito de espaço escolar edificado, as suas sucessivas alterações e usos, as suas configurações e morfologias, que refletem ideologias e/ou conceções pedagógicas predominantes em cada época, na cultura e tradição escolar (ESCOLANO BENITO, 1992, p. 63). Esses espaços são contendores, ao conterem, ao produzirem e conservarem património de cultura material da educação ou escolar. Um património constituído por espaços e edifícios (arquitetura), por objetos procedentes do exterior (livros de texto, material científico e didático, mobiliário, artefatos, símbolos, mapas, etc.) ou produzidos no meio escolar (cadernos de exercícios, trabalhos manuais, exames, dossiês, diários, diplomas, certificados, fotografias, processos, etc.) (VIÑAO FRAGO, 2008, p. 19). Com a generalização da escolaridade essa memória escolar dos espaços e da sua cultura produzida convertese em memória social e histórica.

\section{Referências}


ALEGRE, Ma Alexandra. A arquitectura escolar: o edifício liceu em Portugal (1882-1978). Tese (Dissertação para obtenção do grau de Doutor em Arquitectura) no Instituto Superior Técnico da ULisboa. Lisboa: UTL, 2009

BARROSO, J. O século da escola, do mito da reforma à reforma de um mito. $O$ século da escola, entre a utopia e a burocracia. Porto/Rio Tinto: ASA, 2001

BATANAZ, L. Organización del espacio, del tiempo y de los recursos en las instituciones escolares. In: BATANAZ, L. (dir.), Organización Escolar. Bases científicas para el desarrollo de las instituciones educativas. Córdoba: SPUC, 2003, p. 237-280

BONDIOLI, A. \& NIGITO, G. (coords.). Tiempos, espacios y agrupamientos. Barcelona. Graó, 2011

BURKE, C. Introduction. Containing the school child: architectures and pedagogies. Paedagogica Historica, 41 (4-5), 2005, p. 489-494

CARVALHO, Rómulo de. História do ensino em Portugal desde a fundação da nacionalidade até ao fim do regime de Salazar-Caetano. Lisboa: F.C.G., 1986.

CERTEAU, M. A invenção do cotidiano. Petrópolis: Vozes, 1996

COLOM, A. J. Discurso educativo y semântica de los espacios escolares. Bordón, 57 (1), 2005, p. 99-112

DOMĖNECH, J. \& VIÑAS, J. La organización del espacio y del tiempo en el centro educativo. Barcelona. Editorial Graó, 1997

DUDEK, M. Architecture of Schools. The new learning environments. Boston: A. Press, 2000

ESCOLANO BENITO, A. Tiempo y Educación. Notas para una genealogia del almanaque escolar. Rev. de Educación - Rev. Interuniversitaria, 298, 1992, 55-79

ESCOLANO BENITO, A. Tiempos y espacios. Ensayos históricos. Madrid: Biblioteca Nueva, 2000

ESCOLANO BENITO, A. Escenografías escolares: Espacios y actores. In: VV. AA., Etnohistoria de la Escuela. Burgos : Universidad de Burgos, 2003, p. 365-375

ESCOLANO BENITO, A. La escuela en la memoria. In: LOMAS, C. (coord.), Lecciones contra el olvido. Memoria de la educación y educación de la memoria. Barcelona: Octaedro, 2011, p. 61-76

FELGUEIRAS, M. Ma Louro. Para um museu vivo da escola primária: trajectória de uma investigação. In: MAGALHÃES, J. (org.), Fazer e Ensinar História da Educação. Braga: Instituto de Educação e Psicologia/UMinho, 1998, p. 147-154 


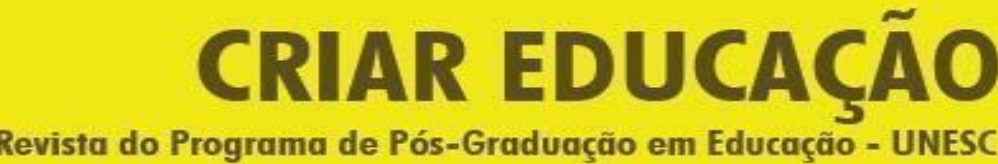

Criar Educação, Criciúma, v. 9, n²2, Edição Especial 2020.- PPGE - UNESC - ISSN 2317-2452

GARCÍA DEL DUJO, A. \& MUÑOZ RODRíGUEZ, J. M. Pedagogía de los espacios. Esbozo de un horizonte educativo para el siglo XXI. Rev. Española de Pedagogía, 228, 2004, p. 257-278

NÓVOA, A. S. Evidentemente. Histórias da Educação. Porto: Ed. ASA. 2005

PINTASSILGO, J. ; COSTA, R. A construção histórica do tempo escolar em Portugal (do final do séc. XIX às primeiras décadas do séc. XX). In : GÓMEZ FERNÁNDEZ, R. ; ESPIGADO TOCINO, M.G. ; BEAS MIRANDA, M. (coord.), La Escuela y sus escenarios. Cádiz/El Puerto de Santa Maria: Concejaría de Cultura del Ayuntamiento, 2007, p. 105-130

ROMANÁ BLAY, T. Arquitectura y Educación : perspectivas y dimensiones. Rev. Española de Pedagogía, 228, 2004, p. 199-220

TRILLA, J. (coord.) El legado pedagógico del siglo XX para la escuela del siglo XXI. Barcelona: Graó, 2002

VIÑAO FRAGO, A. Del espacio escolar y la escuela como lugar: Propuestas y cuestiones. Historia de la Educación, 12-13, 1993-1994, p. 17-74.

VINÃO FRAGO, A. Espacios escolares, funciones y tareas: La ubicación de la dirección escolar en la escuela graduada. Rev. Española de Pedagogía, Año LXII, 228, mayo-agosto 2004, p. 279-304

VIÑAO FRAGO, A. El espacio escolar. Viejas cuestiones, nuevos escenarios. In: ESCOLANO, A. (dir.), Historia ilustrada de la escuela en España. Dos siglos de perspectiva histórica. Madrid: Fundación Germán Sánchez Ruipérez, 2006, 289-308.

VIÑAO FRAGO, A. Escolarización, edificios y espacios escolares (Monográfico). CEE Participación Educativa, 7, marzo, 2008, p. 16-27

Recebido abril de 2019 Aprovado junho de 2020 